\title{
Lymph Node Negative Colorectal Cancers with Isolated Tumor Deposits Should Be Classified and Treated As Stage III
}

\author{
E. J. Th. Belt, $\mathrm{MD}^{1}$, M. F. M. van Stijn, $\mathrm{MD}^{1}$, H. Bril, MD, $\mathrm{PhD}^{2}$, E. S. M. de Lange-de Klerk, MD, $\mathrm{PhD}^{3}$, \\ G. A. Meijer, $\mathrm{MD}, \mathrm{PhD}^{4}$, S. Meijer, $\mathrm{MD}, \mathrm{PhD}^{1}$, and $\mathrm{H}$. B. A. C. Stockmann, $\mathrm{MD}, \mathrm{PhD}^{5}$ \\ ${ }^{1}$ Department of Surgery, VU Medical Centre, Amsterdam, The Netherlands; ${ }^{2}$ Department of Pathology, Kennemer \\ Gasthuis, Haarlem, The Netherlands; ${ }^{3}$ Department of Epidemiology and Biostatistics, VU Medical Centre, Amsterdam, \\ The Netherlands; ${ }^{4}$ Department of Pathology, VU Medical Center, Amsterdam, The Netherlands; ${ }^{5}$ Department of Surgery, \\ Kennemer Gasthuis, Haarlem, The Netherlands
}

\begin{abstract}
Background. The prognostic role of pericolic or perirectal isolated tumor deposits (ITDs) in node-negative colorectal cancer (CRC) patients is unclear. Rules to define ITDs as regional lymph node metastases changed in subsequent editions of the TNM staging without substantial evidence. Aim of this study was to investigate the correlation between ITDs and disease recurrence in stage II and III CRC patients.

Materials and Methods. The medical files of 870 CRC patients were reviewed. Number, size, shape, and location pattern of all ITDs in node-negative patients were examined in relation to involvement of vascular structures and nerves. The correlation between ITDs and the development of recurrent disease was investigated.

Results. Disease recurrence was observed in $50.0 \%$ of stage II patients with ITDs (13 of 26), compared with $24.4 \%$ of stage II patients without ITDs (66 of 270) $(P<.01)$. Disease-free survival of ITD-positive stage II patients was comparable with that of stage III patients. Also within stage III, more recurrences were observed in ITD-positive patients compared with ITD-negative patients (65.1 vs. $39.1 \%$, respectively). No correlation was found between size of ITDs and disease recurrence. More recurrences were seen in patients with irregularly shaped ITDs compared with patients with 1 or more smooth ITDs present.
\end{abstract}

(C) The Author(s) 2010. This article is published with open access at Springerlink.com

First Received: 18 February 2010;

Published Online: 13 July 2010

E. J. Th. Belt, MD

e-mail: ericbelt@hotmail.com
Conclusions. Because of the high risk of disease recurrence, all node-negative stage II patients with ITDs, regardless of size and shape, should be classified as stage III, for whom adjuvant chemotherapy should be considered.

With more than 600,000 deaths worldwide per year, colorectal cancer (CRC) is the third most common form of cancer and the second leading cause of cancer-related death in the Western world. ${ }^{1}$

Currently, the primary method for assessing prognostic differences among patients is the tumor-node-metastasis (TNM) staging system, developed by the American Joint Committee on Cancer and the International Union Against Cancer (UICC). ${ }^{2}$ Main therapeutic decisions are based on this classification.

Isolated tumor deposits (ITDs) are defined as focal aggregates of adenocarcinoma located in the pericolic or perirectal fat discontinuous with the primary tumor and unassociated with a lymph node. Whether these ITDs should be considered as lymph node involvement when staging the disease has been the subject of discussion for many years, resulting in changes in classification of the disease in subsequent editions of the TNM staging system. Before TNM5, the 5th edition published in 1997, pericolic and perirectal isolated tumor deposits were not classified as positive lymph nodes, regardless of their size and shape, but were classified in the pT-category as $\mathrm{pT} 3 .^{3}$ In TNM5, the 3-mm rule was introduced, which states that any mesocolic or mesorectal tumor deposit of $3 \mathrm{~mm}$ in size or more should be considered as involved lymph node. ${ }^{4}$ In the absence of other evidence of lymph node involvement, this rule resulted in the reclassification of the disease from stage 
II, for which adjuvant treatment is not indicated routinely, to stage III, for which it is. The 3-mm rule was not introduced on the basis of trial data, but on the basis of unsubstantiated, unpublished work. ${ }^{5}$ In TNM6, the current edition which was published in 2002 , the $3-\mathrm{mm}$ rule was withdrawn. In this edition, the tumor nodule without evidence of residual lymph node is classified in the $\mathrm{pN}$ category when the nodule has the "form and the smooth contour of a lymph node. ${ }^{6}$ However, also this contour rule lacks support from clinical evidence and reproducibility is poor, because of the absence of appropriate guidelines. ${ }^{5}$

In the present study we investigated the prevalence of ITDs in CRC and the relevance of ITDs and their size, shape, and location pattern on clinical outcome in stage II CRC patients.

\section{PATIENTS AND METHODS}

Between 1996 and 2005, a total of 870 patients underwent surgical resection for colorectal cancer (CRC) at the Kennemer Gasthuis hospital in Haarlem, the Netherlands.

The following information for each patient was obtained: date of birth, date of surgery, planned or emergency surgery (because of bowel obstruction and/or perforation), location of the primary tumor (coecal, ascending, transverse, descending, sigmoid, rectosigmoid, rectal), adjuvant therapy (radiation and chemotherapy), date and site of first recurrence, and cause of death (CRC related or other cause). Recurrent disease was defined as either a peritoneal recurrence or distant metastasis.

Information on pathological variables was obtained from the histopathology reports.

Tumor stage was classified according to TNM $4 .^{3}$ The following data were collected: tumor size, tumor and nodal stage, number of total nodes examined, presence of isolated tumor deposits, differentiation grade, ulceration, mucinous differentiation, and angioinvasion.

From stage II patients $(n=325)$ with reported ITDs, all available slides were reviewed by an independent pathologist who was unaware of clinical outcome. Apart from ITD characteristics, that is, number, size, shape (smooth or irregular, Fig. 1), presence of vasoinvasive and neuroinvasive growth were scored. Patients with a history of colorectal malignancy and those with irradical (macroscopically or microscopically) resections were excluded from the study. Patients with a follow-up period shorter than 3 months after surgery (due to death or lost in follow up) were excluded from the disease recurrence analysis.

\section{Statistical Analysis}

Chi-square test was applied to assess differences between groups. Survival analysis was conducted using the

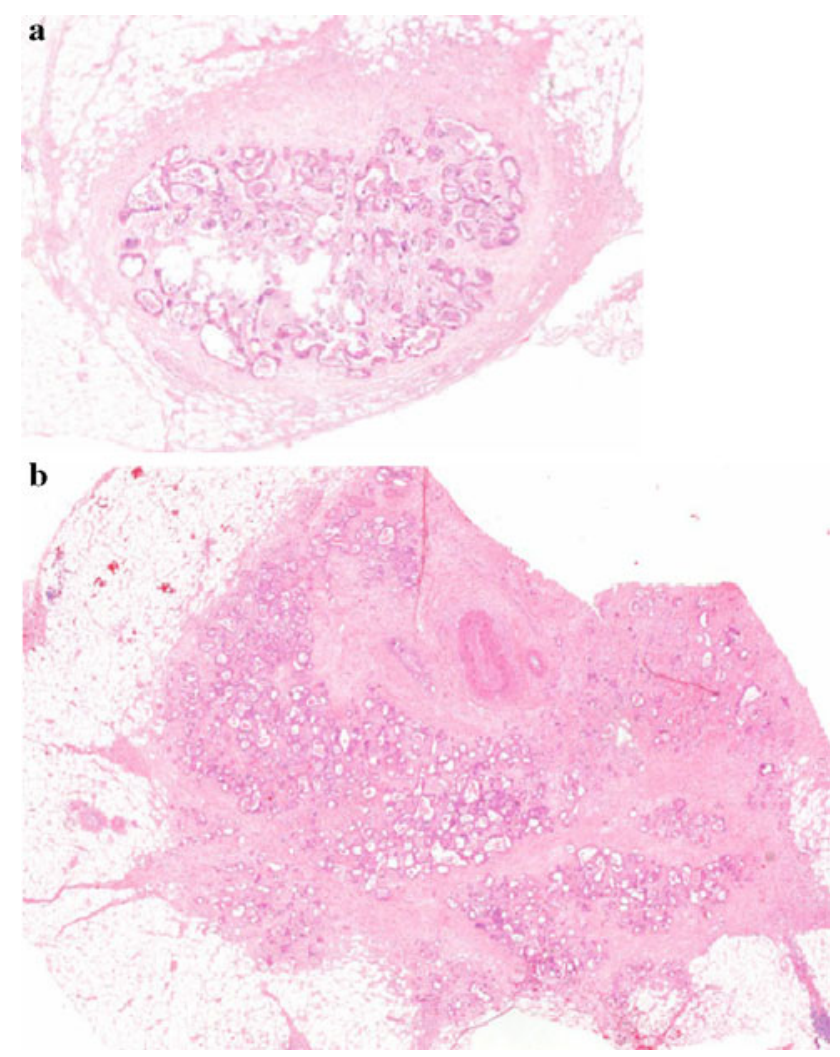

FIG. 1 Example of an isolated tumor deposit (ITD) with a smooth (a) and an irregular (b) contour

Kaplan-Meier method and the log-rank test. Multivariate analysis was performed using stepwise logistic regression. A $P$ value of $\leq .05$ was considered statistically significant. Statistical analysis was performed with SPSS 15.0 for Windows, SPSS Inc., Chicago, IL.

\section{RESULTS}

The 870 patients had a mean age of 70.8 years, 466 males $(53.6 \%)$ and 404 females $(46.4 \%)$. Of all patients, $169(19.4 \%)$ were classified as AJCC stage I, 325 (37.4\%) as stage II, $229(26.3 \%)$ as stage III, and 147 patients (16.9\%) as stage IV (Table 1).

In 667 patients (77\%) the tumor was located in the colon and in 203 patients $(23 \%)$ in the rectum. Of the latter group, 136 patients $(67 \%)$ received perioperative radiotherapy (105 preoperative and 31 postoperative). Median follow-up was 47.3 months (range 0.0-150.8 months).

The mean number of lymph nodes retrieved for pathological examination was 7.9 (SD 5.1). Recurrent disease occurred in 12 patients (7.4\%) in stage I, in $79(26.7 \%)$ in stage II, and in 94 patients (44.3\%) in stage III.

In 127 of 870 patients (14.8\%), ITDs were observed. The incidence of patients with ITDs increased with higher tumor stage. No stage I patients had ITDs, $30(9.2 \%)$ in 
TABLE 1 Clinical and pathological characteristics of 870 CRC patients
Values in parentheses are percentages unless stated otherwise

${ }^{\text {a }}$ Patients who died within 3 months after surgery are excluded

${ }^{b}$ Patients with stage IV disease are not included

\begin{tabular}{|c|c|c|c|c|c|}
\hline & $\begin{array}{l}\text { Stage I } \\
(n=169)\end{array}$ & $\begin{array}{l}\text { Stage II } \\
(n=325)\end{array}$ & $\begin{array}{l}\text { Stage III } \\
(n=229)\end{array}$ & $\begin{array}{l}\text { Stage IV } \\
(n=147)\end{array}$ & $\begin{array}{l}\text { Overall } \\
(\mathrm{n}=870)\end{array}$ \\
\hline \multicolumn{6}{|l|}{ Sex } \\
\hline Male & $81(47.9)$ & $169(52.0)$ & $130(56.8)$ & $86(58.5)$ & $466(53.6)$ \\
\hline Female & $88(52.1)$ & $156(48.0)$ & $99(43.2)$ & $61(41.5)$ & $404(46.4)$ \\
\hline \multicolumn{6}{|l|}{ Age (years) } \\
\hline Mean (SD) & $70.8(11.5)$ & $71.6(11.6)$ & $70.6(11.6)$ & $69.011 .9)$ & $70.8(11,7)$ \\
\hline Median (range) & $72.6(27.6-89.3)$ & $73.2(28.5-94.4)$ & $72.5(34.5-94.0)$ & $70.6(30.8-90.0)$ & $72.6(27.6-94.4)$ \\
\hline \multicolumn{6}{|l|}{ Emergency surgery } \\
\hline Yes & $1.0(0.6)$ & $38(11.7)$ & $37(16.2)$ & $31(21.1)$ & $107(12.3)$ \\
\hline No & $168(99.4)$ & $287(88.3)$ & $192(83.8)$ & $116(78.9)$ & $763(87.7)$ \\
\hline \multicolumn{6}{|l|}{ Tumor location } \\
\hline Colon & $106(63.3)$ & $260(80.0)$ & $177(77.3)$ & $123(83.7)$ & $667(76.7)$ \\
\hline Rectum & $62(36.7)$ & $65(20.0)$ & $52(22.7)$ & $24(16.3)$ & $203(23.3)$ \\
\hline \multicolumn{6}{|l|}{ Tumor size $(\mathrm{mm})$} \\
\hline Mean (SD) & $35.7(16.4)$ & $42.6(20.2)$ & $41.4(19.5)$ & $45.7(23.7)$ & $41.4(20.2)$ \\
\hline Median (range) & $30.0(10-100)$ & $40.0(10-130)$ & $40.0(10-150)$ & $40.0(10-180)$ & $40.0(10-180)$ \\
\hline \multicolumn{6}{|l|}{ Tumor stage } \\
\hline $\mathrm{T} 1$ & $36(21.8)$ & - & $6(2.6)$ & $0(0)$ & $42(4.8)$ \\
\hline $\mathrm{T} 2$ & $133(78.7)$ & - & $25(10.9)$ & $6(4.1)$ & $165(19.0)$ \\
\hline $\mathrm{T} 3$ & - & $287(88.3)$ & $177(77.3)$ & $92(62.6)$ & $555(63.8)$ \\
\hline $\mathrm{T} 4$ & - & $38(11.7)$ & $21(9.2)$ & $49(33.3)$ & $108(12.4)$ \\
\hline \multicolumn{6}{|l|}{ Nodal stage } \\
\hline No & $169(100)$ & $325(100)$ & - & $51(34.7)$ & $546(62.8)$ \\
\hline N1 & - & - & $159(69.4)$ & $52(35.4)$ & $210(24.1)$ \\
\hline $\mathrm{N} 2$ & - & - & $70(30.6)$ & $44(29.9)$ & $114(13.1)$ \\
\hline \multicolumn{6}{|c|}{ No. of nodes examined } \\
\hline Mean (SD) & $5,7(3.9)$ & $7.9(5.2)$ & $9.8(5.2)$ & $7.2(4.6)$ & $7.9(5.1)$ \\
\hline Median (range) & $5(0-22)$ & $7(0-38)$ & $9(1-28)$ & $6(0-24)$ & $7.0(0-38)$ \\
\hline \multicolumn{6}{|c|}{ Isolated tumor deposits } \\
\hline Yes & $0(0)$ & $30(9.2)$ & $46(20.1)$ & $51(34.7)$ & $127(14.6)$ \\
\hline No & $169(100)$ & $295(90.8)$ & $183(79.9)$ & $96(65.3)$ & $743(85.4)$ \\
\hline \multicolumn{6}{|l|}{ Histological grade } \\
\hline Well & $22(13.0)$ & $19(5.8)$ & $10(4.4)$ & $1(0.7)$ & $121(13.9)$ \\
\hline Moderately & $138(81.7)$ & $267(82.2)$ & $176(76.9)$ & $116(78.9)$ & $697(80.1)$ \\
\hline Poorly & $9(5.3)$ & $39(12.0)$ & $43(18.8)$ & $30(20.4)$ & $52(6.0)$ \\
\hline \multicolumn{6}{|c|}{ Mucinous differentiation } \\
\hline Yes & $25(14.8)$ & $62(19.1)$ & $51(22.3)$ & $26(17.7)$ & $164(18.9)$ \\
\hline No & $144(85.2)$ & $263(80.9)$ & $178(77.7)$ & $121(82.3)$ & $706(81.1)$ \\
\hline \multicolumn{6}{|l|}{ Ulceration } \\
\hline Present & $78(46.2)$ & $243(74.8)$ & $177(77.3)$ & $102(69.4)$ & $600(69.0)$ \\
\hline Absent & $91(53.8)$ & $82(25.2)$ & $52(22.7)$ & $45(30.6)$ & $270(31.0)$ \\
\hline \multicolumn{6}{|l|}{ Angioinvasion } \\
\hline Present & $3(1.8)$ & $38(11.7)$ & $79(34.5)$ & $68(46.3)$ & 188 (21.6) \\
\hline Absent & $166(98.2)$ & $287(88.3)$ & $150(65.5)$ & $79(53.7)$ & $682(78.4)$ \\
\hline Recurrent disease $^{a}$ & & & & $\mathrm{~b}$ & b \\
\hline Yes & $12(7.4)$ & $79(26.7)$ & $94(44.3)$ & - & $185(27.7)$ \\
\hline No & 149 (92.6) & $217(73.3)$ & $118(55.7)$ & - & $484(72.3)$ \\
\hline \multicolumn{6}{|l|}{ Follow-up (months) } \\
\hline Median (range) & $66.8(0.1-150.8)$ & $57.3(0.0-139.6)$ & $44.8(0.0-148.6)$ & $11.9(0.0-99.3)$ & $47.3(0.0-150.8)$ \\
\hline
\end{tabular}


stage II, $46(20.1 \%)$ in stage III, and $51(34.7 \%)$ in stage IV $(P<.01)$.

In total, ITDs were observed in 45 of 546 node-negative patients, compared with 82 of 324 node-positive patients ( 8.2 vs. $25.3 \%, P<.01)$.

\section{Stage II CRC Patients}

Clinicopathological characteristics of stage II patients are described in Table 2. Angioinvasive growth of the primary tumor was observed more frequently in patients with ITDs compared with ITD-negative patients (40.0 vs. $8.8 \%$, respectively, $P<.01)$. Of 26 patients with ITDs included in the recurrent disease analysis, $50.0 \%$ developed a recurrence, compared with $24.4 \%$ of 270 patients without ITDs $(P<.01)$. In a multivariate analysis, the presence of ITDs was maintained as an independent risk of disease recurrence when adjusted for other known risk factors, namely T-stage, differentiation grade, and angioinvasion of the primary tumor, emergency surgery, and total lymph nodes examined (mean number used as cut-off) $(P=.01$, odds ratio $[\mathrm{OR}]: 3.1 ; 95 \%$ confidence interval $[95 \%$ $\mathrm{CI}]: 1.4-6.9){ }^{7}$ Disease-free survival curves are displayed in Fig. 2a. Figure $2 b$ shows that the disease-free survival of stage II patients with ITDs is comparable to that of stage III patients. For patients with recurrent disease, no significant difference was seen in the site of recurrence (local or distant) between ITD-positive patients compared with ITDnegative patients.

Of the 30 stage II patients with ITDs, 4 died within 3 months after surgery. The characteristics of the remaining 26 patients are described in Table 3. In the group of patients with recurrent disease, the primary tumor showed more frequently vascular invasion compared to the patients without recurrence ( 61.5 vs. $23.1 \%$, respectively, $P<.05$ ) and was located more frequently in the rectum than in the colon, although this difference is not statistically significant (46.2 and $15.4 \%$ respectively, $P=.09$ ). In half of the patients with ITDs, more than 1 ITD was found in the resection specimen. The recurrence rate in this group was comparable to patients with only 1 ITD (53.8 vs. $46.2 \%$, respectively, $P=.70$ ).

A total of 20 patients $(76.9 \%)$ had at least 1 ITD of $3 \mathrm{~mm}$ or larger size and 11 patients $(42.3 \%)$ had at least 1 ITD with a smooth contour. The presence of larger $(\geq 3.0 \mathrm{~mm})$ ITDs was similar in the recurrence group compared with the nonrecurrence group. Smooth ITDs were found more often in patients without recurrence (8 vs. 3 respectively, $P<.05)$.

In total, 52 ITDs were found in 30 patients. A smooth contour was observed in 34 ITDs $(65.4 \%)$, whereas in 18 $(34.6 \%)$ an irregular shape was seen. More than half of the ITDs were not located adjacent to a nerve or vessel.
Perivascular or intravascular location was observed in 19 ITDs $(35.5 \%)$, and close proximity to a nerve was seen in 10 ITDs $(19.2 \%)$.

In 17 of the 26 ITD-positive patients $(64.4 \%)$ analyzed for disease recurrence, the ITDs were not adjacent to a nerve or vessel (Table 4). In 5 of the remaining 9 patients, ITDs did not show a single location pattern, but both perineural and perivascular or intravascular locations of ITDs was seen. In patients with disease recurrence, more perivascular or intravascular ITDs were seen (6 vs. 2 respectively, $P=.09$ ).

\section{Stage III Patients}

For stage III patients recurrent disease was observed in 94 patients $(44.3 \%$, Table 1$)$. Within stage III patients, ITDpositive patients $(n=43)$ had a higher recurrence rate than ITD-negative $(n=169)$ patients $(65.1$ vs. $39.1 \%, P<.01)$. Disease-free survival curves are displayed in Fig. 2c.

Considering only stage III colon cancer patients who were treated with (fluorouracil-based) adjuvant chemotherapy $(n=83), 63.2 \%$ of ITD-positive patients had recurrent disease, compared with $43.8 \%$ of ITD-negative patients, but this difference lacks statistical significance $(P=.14)$, possible due to the small number of cases.

\section{DISCUSSION}

Dependent on the method of examination and the selection of cases, a large variation in the incidence of ITDs has been reported in a review study, ranging from 4.5 to $45 \%$ of cases. ${ }^{5}$ The presence of ITDs in the absence of lymph node metastases were present in only 3-25\% (mean $8 \%$ ) of patients. In our study, ITDs were observed in $14.6 \%$ of 870 stage I-IV CRC patients, with $9.2 \%$ in stage II and $6.5 \%$ when adding the stage I patients to the node-negative group.

Different theories have been proposed concerning the origin of isolated tumor deposits. Already in 1935 Gabriel et al. described their existence and concluded that they were the result of vascular tumor dissemination. ${ }^{8}$ Recent studies have demonstrated strong correlations between the presence of ITDs and vascular invasive growth of the primary tumor. ${ }^{9-11}$ In the present study, however, we found that only $35.5 \%$ of the ITDs showed a perivascular or intravascular location. However, since histological sections only provide a 2-dimensional sample of the 3-dimensional tissue, sampling errors may occur, leading to underestimating the prevalence of ITDs associated with vessels.

Possibly, ITDs could actually be lymph node metastases, in which the pre-existing lymph node is no longer recognizable because of destruction of lymph node tissue by tumor cells. As in the present study, several other 
TABLE 2 Clinical and pathological characteristics of stage II CRC patients
Values in parentheses are percentages unless stated otherwise

${ }^{\text {a }}$ Patients who died within 3 months after surgery are excluded

\begin{tabular}{|c|c|c|c|c|}
\hline & $\begin{array}{l}\text { Overall } \\
(n=325)\end{array}$ & $\begin{array}{l}\text { ITD positive } \\
(n=30)\end{array}$ & $\begin{array}{l}\text { ITD negative } \\
(n=295)\end{array}$ & $P$ value \\
\hline \multicolumn{5}{|l|}{ Sex } \\
\hline Male & $169(52.0)$ & $18(60.0)$ & $151(51.2)$ & \multirow[t]{2}{*}{ NS } \\
\hline Female & $156(48.0)$ & $12(40.0)$ & $144(48.8)$ & \\
\hline \multicolumn{5}{|l|}{ Age (years) } \\
\hline Mean (SD) & $71.6(11.6)$ & $73.8(12.0)$ & $71.3(11.6)$ & \multirow[t]{2}{*}{ NS } \\
\hline Median (range) & $73.2(28.5-94.4)$ & $79.1(45.5-94.4)$ & $73.0(28.5-94.0)$ & \\
\hline \multicolumn{5}{|l|}{ Tumor location and adjuvant therapy } \\
\hline Colon & $260(80.0)$ & $22(73.3)$ & $238(80.7)$ & NS \\
\hline With postoperative chemotherapy & $36(13.8)$ & $5(22.7)$ & $29(12.2)$ & \multirow[t]{2}{*}{ NS } \\
\hline Without postoperative chemotherapy & $224(86.2)$ & $17(77.3)$ & $209(87.8)$ & \\
\hline Rectum & $65(20.0)$ & $8(26.7)$ & $57(19.3)$ & NS \\
\hline With perioperative radiotherapy & $50(23.1)$ & $7(87.5)$ & $43(75.4)$ & NS \\
\hline Without perioperative radiotherapy & $15(76.9)$ & $1(12.5)$ & $14(24.6)$ & NS \\
\hline \multicolumn{5}{|l|}{ Emergency surgery } \\
\hline Yes & $38(11.7)$ & $3(10.0)$ & $35(11.9)$ & \multirow[t]{2}{*}{ NS } \\
\hline No & $287(88.3)$ & $27(90.0)$ & $260(88.1)$ & \\
\hline \multicolumn{5}{|l|}{ Tumor size $(\mathrm{mm})$} \\
\hline Mean (SD) & $42.6(20.2)$ & $37.0(17.3)$ & $43.1(20.5)$ & \multirow[t]{2}{*}{ NS } \\
\hline Median (range) & $40.0(10-130)$ & $30.0(20-100)$ & $40.0(10-130)$ & \\
\hline \multicolumn{5}{|l|}{ Tumor stage } \\
\hline $\mathrm{T} 3$ & $287(88.3)$ & $26(86.7)$ & $261(88.5)$ & NS \\
\hline $\mathrm{T} 4$ & $38(11.7)$ & $4(13.3)$ & $34(11.5)$ & NS \\
\hline \multicolumn{5}{|l|}{ No. of nodes examined } \\
\hline Mean (SD) & $7.9(5.2)$ & $6.7(4.4)$ & $8.0(5.3)$ & \multirow[t]{2}{*}{ NS } \\
\hline Median (range) & $7.0(0-38)$ & $5.5(0-16)$ & $7.0(0-38)$ & \\
\hline \multicolumn{5}{|l|}{ Histological grade } \\
\hline Well & $19(5.8)$ & 0 & $19(6.4)$ & NS \\
\hline Moderately & $267(82.2)$ & $27(90.0)$ & $240(81.4)$ & NS \\
\hline Poorly & $39(12.0)$ & $3(10.0)$ & $36(12.2)$ & NS \\
\hline \multicolumn{5}{|l|}{ Mucinous differentiation } \\
\hline Yes & $62(19.1)$ & $5(16.7)$ & $57(19.3)$ & \multirow[t]{2}{*}{ NS } \\
\hline No & $263(80.9)$ & $25(83.3)$ & $238(80.7)$ & \\
\hline \multicolumn{5}{|l|}{ Ulceration } \\
\hline Yes & $243(74.8)$ & $24(80.0)$ & $219(74.2)$ & \multirow[t]{2}{*}{ NS } \\
\hline No & $82(25.2)$ & $6(20.0)$ & $76(25.8)$ & \\
\hline \multicolumn{5}{|l|}{ Angioinvasion } \\
\hline Present & $38(11.7)$ & $12(40.0)$ & $26(8.8)$ & \multirow[t]{2}{*}{$<.001$} \\
\hline Absent & $287(88.3)$ & $18(60.0)$ & $269(91.2)$ & \\
\hline \multicolumn{5}{|l|}{ Recurrent disease $^{\mathrm{a}}$} \\
\hline No & $217(73.3)$ & $13(50.0)$ & $204(75.6)$ & \multirow[t]{2}{*}{.005} \\
\hline Yes & $79(26.7)$ & $13(50.0)$ & $66(24.4)$ & \\
\hline Local & & $6(46.2)$ & $29(43.9)$ & \multirow[t]{2}{*}{ NS } \\
\hline Distant & & $7(53.8)$ & $37(56.1)$ & \\
\hline \multicolumn{5}{|l|}{ Follow-up (months) } \\
\hline Median (range) & $57.3(0.0-139.6)$ & $58.5(0.3-129.2)$ & $57.3(0.0-139.6)$ & NS \\
\hline
\end{tabular}

studies have demonstrated that the incidence of ITDs is higher in patients with lymph node metastases than in patients without nodal involvement. ${ }^{11-14}$ Moreover, ITDs occur more often in patients with extracapsular growth of lymph node metastases, compared with patients with lymph node metastases with an intact capsule. ${ }^{11}$ 


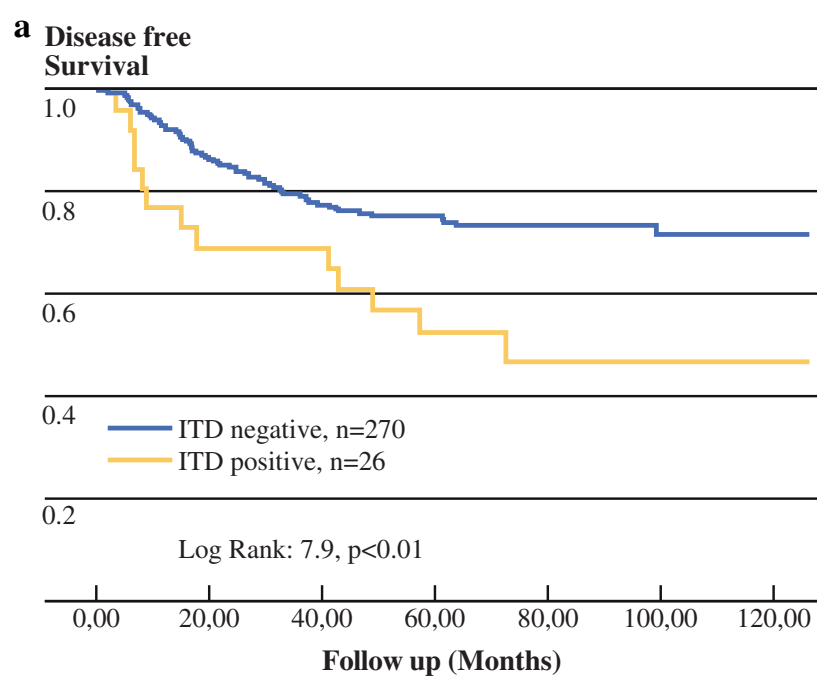

b
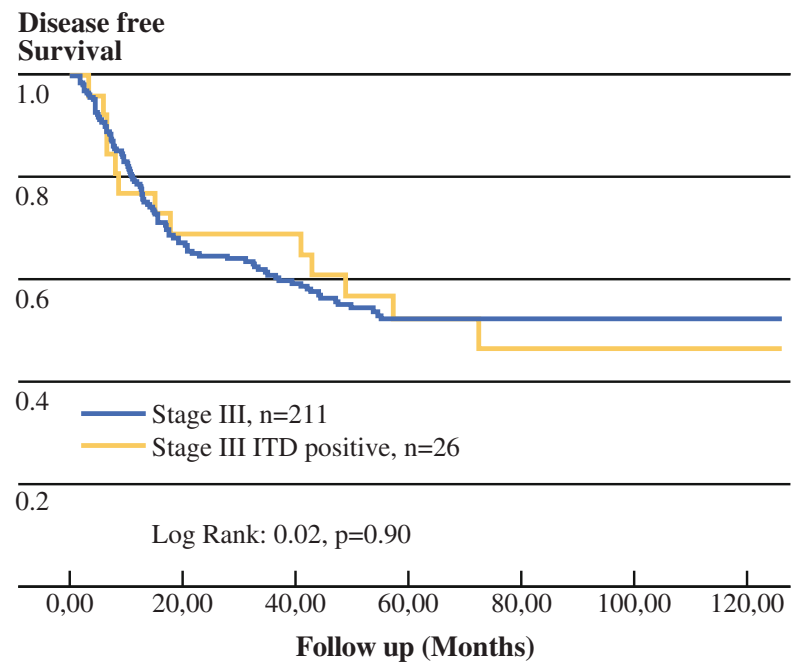

c Disease free

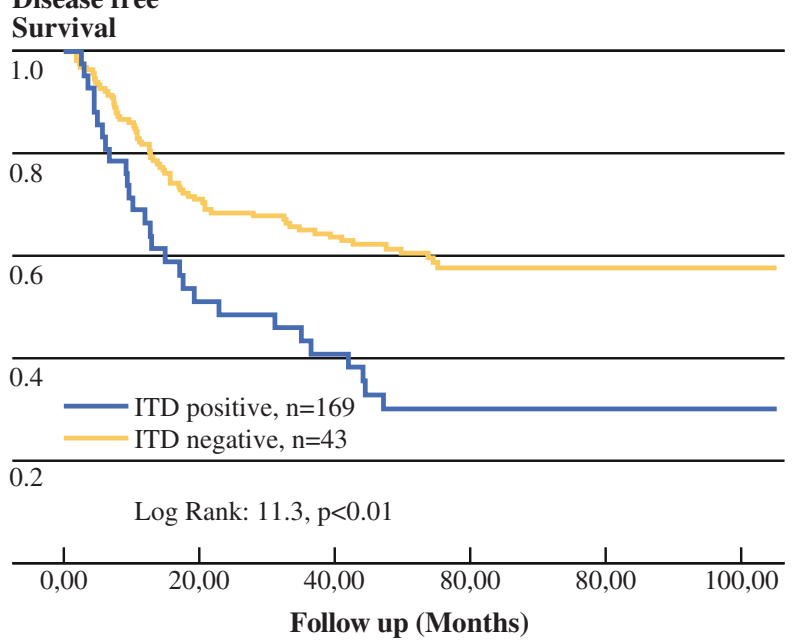

FIG. 2 Disease-free survival curves. a Stage II patients; ITD negative vs ITD positive patients. b Stage III patients vs ITD positive stage II patients. c stage III patients; ITD negative vs ITD positive patients. Patients who died within 3 months after surgery are excluded
Assuming ITDs are located in the course of lymph vessels, recognizable or not, they may reflect "in-transit metastases," defined as metastasis in which cancerous cells spread through a lymph vessel and begin to grow and form a tumor before it reaches the nearest lymph node, a phenomenon well known for melanoma. ${ }^{15}$

Considering the origin of ITDs one should take into account that isolated tumor deposits that are in close proximity of the primary tumor could actually be a continuous tumor extension which by the way of sectioning appears as a separate aggregate.

In some studies the growth pattern of ITDs was investigated categorizing the deposits in endovascular, perivascular, endolymphatic, and perineural growth. In a large number of patients the growth pattern of the ITDs was heterogeneous. ${ }^{14,16}$ In the present study, we observed this phenomenon as well. In more than half of patients with perineural, perivascular, or intravascular locations of ITDs, different patterns were seen.

For ITD-positive patients staged T1-4,N0-2,M0, we found no difference in recurrence rate between colon and rectal cancer, conforming to other studies. ${ }^{5}$

In some studies it has been shown that patients with ITDs have an increased risk of tumor recurrence and worse disease-free survival curves compared with patients without ITDs. ${ }^{9,10,13,14,16-18}$ However, most studies included lymph node positive patients without performing a multivariate regression analysis for the $\mathrm{N}$ stage.

Until now, few data are available on the relation between the presence of ITDs without lymph node metastases and tumor recurrence and survival. Part of this can be explained by the fact that the different interpretations of ITDs in node-negative CRC patients in the subsequent editions of staging systems throughout the past years resulted in a shift of certain stage II patients to stage III. This leads to changes in treatment strategies within the group of node-negative ITD-positive patients, which makes it difficult to study the role of ITDs on outcome of these patients. The patients in the present study were all staged according to the 4th edition of the AJCC TNMstaging system in which node-negative patients with ITDs are not upstaged to stage III, regardless of size and shape of the ITDs. ${ }^{3}$ This made the study population very suitable for analyzing the role of ITDs in node-negative patients.

In this study we showed a significantly worse diseasefree survival for stage II patients with ITDs having a 50\% recurrence rate, compared with $24.4 \%$ for ITD-negative patients. Disease-free survival of ITD-positive stage II patients was comparable to stage III patients.

Some authors concluded that increasing numbers of ITD are associated with a poor prognosis, while others did 
TABLE 3 Clinical and pathological characteristics of ITD positive stage II CRC patients $^{\mathrm{a}}$
Values in parentheses are percentages unless stated otherwise

${ }^{a}$ Patients who died within 3 months after surgery are excluded

\begin{tabular}{|c|c|c|c|c|}
\hline & $\begin{array}{l}\text { Overall } \\
(n=26)\end{array}$ & $\begin{array}{l}\text { Patients } \\
\text { with disease } \\
\text { recurrence } \\
(n=13)\end{array}$ & $\begin{array}{l}\text { Patients without } \\
\text { disease recurrence } \\
(n=13)\end{array}$ & $P$ value \\
\hline \multicolumn{5}{|l|}{ Tumor location and adjuvant therapy } \\
\hline Colon & $18(69.2)$ & $7(53.8)$ & $11(84.6)$ & \\
\hline With postoperative chemotherapy & $5(27.8)$ & $1(14.3)$ & $4(36.4)$ & \multirow[t]{2}{*}{ NS } \\
\hline Without postoperative chemotherapy & $13(72.2)$ & $6(85.7)$ & $7(63.6)$ & \\
\hline Rectum & $8(30.8)$ & $6(46.2)$ & $2(15.4)$ & .09 \\
\hline With perioperative radiotherapy & $6(75.0)$ & $5(83.3)$ & $2(100)$ & NS \\
\hline Without perioperative radiotherapy & $2(25.0)$ & $1(16.7)$ & 0 & \\
\hline \multicolumn{5}{|l|}{ Tumor size (mm) } \\
\hline Mean (SD) & $36.0(17.5)$ & $33.6(14.3)$ & $38.1(20.2)$ & \multirow[t]{2}{*}{ NS } \\
\hline Median (range) & $30.0(20-100)$ & $30.0(20-70)$ & $35.0(20-100)$ & \\
\hline \multicolumn{5}{|l|}{ Tumor stage } \\
\hline $\mathrm{T} 3$ & $25(96.2)$ & $13(100)$ & $12(92.3)$ & \multirow[t]{2}{*}{ NS } \\
\hline $\mathrm{T} 4$ & $1(3.8)$ & $0(0)$ & $1(7.7)$ & \\
\hline \multicolumn{5}{|l|}{ No. of nodes examined } \\
\hline Mean (SD) & $5.7(4.1)$ & $5.1(5.0)$ & $6.2(3.0)$ & \multirow[t]{2}{*}{ NS } \\
\hline Median (range) & $4.5(1-14)$ & $3.0(1-14)$ & $5.0(2-11)$ & \\
\hline \multicolumn{5}{|l|}{ Histological grade } \\
\hline Well & 0 & 0 & 0 & \multirow[t]{3}{*}{ NS } \\
\hline Moderately & $23(88.5)$ & $13(100)$ & $10(76.9)$ & \\
\hline Poorly & $3(11.5)$ & 0 & $3(23.1)$ & \\
\hline \multicolumn{5}{|l|}{ Angioinvasion } \\
\hline Present & $11(42.3)$ & $8(61.5)$ & $3(23.1)$ & \multirow[t]{2}{*}{.047} \\
\hline Absent & $15(57.7)$ & $5(38.5)$ & $10(76.9)$ & \\
\hline \multicolumn{5}{|l|}{ Number of ITDs } \\
\hline 1 & $13(50.0)$ & $6(46.2)$ & $7(53.8)$ & \multirow[t]{3}{*}{ NS } \\
\hline 2 & $11(42.3)$ & $5(38.5)$ & $6(46.2)$ & \\
\hline$\geq 3$ & $2(7.7)$ & $2(15.3)$ & 0 & \\
\hline \multicolumn{5}{|l|}{ Size of ITDs } \\
\hline Only ITDs $<3.0 \mathrm{~mm}$ & $6(23.1)$ & $2(15.4)$ & $4(30.8)$ & \multirow[t]{2}{*}{ NS } \\
\hline$\geq 1 \mathrm{ITD} \geq 3.0 \mathrm{~mm}$ & $20(76.9)$ & $11(84.6)$ & $9(69.2)$ & \\
\hline \multicolumn{5}{|l|}{ Shape of ITDs } \\
\hline Only irregular ITDs & $15(57.7)$ & $10(76.9)$ & $5(38.5)$ & \multirow[t]{2}{*}{.047} \\
\hline$\geq 1$ smooth ITD & $11(42.3)$ & $3(23.1)$ & $8(61.5)$ & \\
\hline
\end{tabular}

TABLE 4 Location pattern of isolated tumor deposits in stage II patients ${ }^{\mathrm{a}}$

\begin{tabular}{llll}
\hline Location & $\begin{array}{l}\text { Overall } \\
(n=26)\end{array}$ & $\begin{array}{l}\text { Patients with disease } \\
\text { recurrence }(n=13)\end{array}$ & $\begin{array}{l}\text { Patients without disease } \\
\text { recurrence }(n=13)\end{array}$ \\
\hline All ITDs not adjacent to nerve or vessel & $17(64.4)$ & $7(53.8)$ & $10(76.9)$ \\
Perineural in $\geq 1$ ITD & $1(3.8)$ & 0 & $1(7.7)$ \\
$\begin{array}{l}\text { Perivascular or intravascular in } \geq 1 \text { ITD } \\
\text { Perineural in } \geq 1 \text { ITD and perivascular or }\end{array}$ & $3(11.5)$ & $3(23.1)$ & 0 \\
$\quad$ intravascular in $\geq 1$ ITD & $5(19.2)$ & $3(23.1)$ & $2(15.4)$ \\
\hline
\end{tabular}

Values in parentheses are percentages unless stated otherwise

a Patients who died within 3 months after surgery are excluded 
not. ${ }^{12,16}$ In this study, we found no correlation between the number of ITDs and the recurrence rate in stage II patients.

Although little evidence is available on the prognostic value of ITDs in lymph node negative patients, the presence of ITDs was first incorporated in the TNM American Joint Committee on Cancer (AJCC) staging manuals in $1997 .{ }^{4}$ In this (5th) edition a tumor nodule larger than $3 \mathrm{~mm}$ in diameter without histological evidence of a residual lymph node in the nodule was classified as regional lymph node metastasis, a smaller nodule was not. Because substantial evidence was missing, this 3-mm rule was abandoned, and in the current (6th) edition of the TNM classification system a contour criterion is applied. ${ }^{6}$ In this edition, tumor nodules without evidence of a residual lymph node that have the form and smooth contour of a lymph node are considered equivalent to regional lymph node metastasis. If a nodule has an irregular contour, it should be classified in the T category. However, as Nagtegaal and Quirke indicated in their review paper, the evidence on which this contour rule is based is weak and reproducibility is poor. ${ }^{5}$

In this study we examined both the size and shape of the ITDs of stage II patients and investigated the correlation with disease recurrence. Taking $3 \mathrm{~mm}$ as cutoff point, we found no correlation between the presence of at least 1 large ITD in the resection specimen and disease recurrence.

Regarding the contour of the ITDs, more patients with only irregularly shaped ITDs developed disease recurrence than patients who had 1 or more smooth ITDs. These findings do not give any support to the notion to consider smooth ITDs to be equivalent to regional lymph node metastasis, as stated in the current edition of the TNM staging system.

\section{Limitations of the Study}

In the Netherlands, standard treatment of stage III colon cancer patients is surgery followed by adjuvant chemotherapy, but this is not always offered to elderly, nonvital patients. For stage II colon cancer patients, chemotherapy is not part of the standard care and only offered to highrisk, vital patients according to the judgment of the local oncosurgical staff. Because of the retrospective design of the study, information on considerations to offer adjuvant chemotherapy was not always available.

For an accurate analysis of the prognostic role of ITDs in stage III CRC patients, one should stratify patients according to adjuvant treatment and lymph node status $(\mathrm{N} 1, \mathrm{~N} 2)$, but the different subgroups are too small to show meaningful results. The same counts for stratification for location of the primary tumor and perioperative radiotherapy.
In conclusion, in this study, we demonstrate that the presence of isolated tumor deposits in node-negative CRC patients is a significant risk factor for developing disease recurrence, regardless of the size, shape, number, and location pattern of the ITDs. In our opinion, all CRC patients with pericolic or perirectal ITDs should be classified as stage III, for whom adjuvant treatment should be considered in order to reduce disease recurrence.

OPEN ACCESS This article is distributed under the terms of the Creative Commons Attribution Noncommercial License which permits any noncommercial use, distribution, and reproduction in any medium, provided the original author(s) and source are credited.

\section{REFERENCES}

1. World Health Organization. http://www.who.int/mediacentre/ factsheets/fs297/en/. (February 2009).

2. American Joint Committee on Cancer. Manual for staging of cancer. Philadelphia: Lippincott-Raven; 1998.

3. Hermanek P, Sobin LH, International Union Against Cancer (UICC). TNM classification of malignant tumours. 4th ed. New York: Springer-Verlag; 1987.

4. Sobin LH, Wittekind CH. International Union Against Cancer (UICC). TNM classification of malignant tumours. 5th ed. New York: Wiley-Liss Publications; 1997.

5. Nagtegaal ID, Quirke P. Colorectal tumour deposits in the mesorectum and pericolon; a critical review. Histopathology. 2007;51:141-9.

6. Sobin LH, Wittekind $\mathrm{CH}$, International Union Against Cancer (UICC). TNM classification of malignant tumours. 6th ed. New York: Wiley-Liss Publications; 2002.

7. Morris EJ, Maughan NJ, Forman D, Quirke P. Who to treat with adjuvant therapy in Dukes B/stage II colorectal cancer? The need for high quality pathology. Gut. 2007;56:1419-25.

8. Gabriel WB, Dukes CE, Bussey HJR. Lymphatic spread in cancer of the rectum. Br J Surg. 1935;23:395-413.

9. Prabhudesai A, Arif S, Finlayson CJ, Kumar D. Impact of microscopic extranodal tumor deposits on the outcome of patients with rectal cancer. Dis Colon Rectum. 2003;46:1531-7.

10. Ueno H, Mochizuki H. Clinical significance of extrabowel skipped cancer infiltration in rectal cancer. Surg Today. 1997;27: 617-22.

11. Ueno H, Mochizuki H, Tamakuma S. Prognostic significance of extranodal microscopic foci discontinuous with primary lesion in rectal cancer. Dis Colon Rectum. 1998;41:55-61.

12. Harrison JC, Dean PJ, el Zeky F, Vander Zwaag R. From Dukes through Jass: pathological prognostic indicators in rectal cancer. Hum Pathol. 1994;25:498-505.

13. Harrison JC, Dean PJ, el Zeky F, Vander Zwaag R. Impact of the Crohn's-like lymphoid reaction on staging of right-sided colon cancer: results of multivariate analysis. Hum Pathol. 1995;26: $31-8$.

14. Ratto C, Ricci R, Rossi C, Morelli U, Vecchio FM, Doglietto GB. Mesorectal microfoci adversely affect the prognosis of patients with rectal cancer. Dis Colon Rectum. 2002;45:733-42.

15. Balch CM, Buzaid AC, Soong SJ, Atkins MB, Cascinelli N, Coit DG, et al. Final version of the American Joint Committee on Cancer staging system for cutaneous melanoma. J Clin Oncol. 2001;19:3635-48.

16. Goldstein NS, Turner JR. Pericolonic tumor deposits in patients with $\mathrm{T} 3 \mathrm{~N}+\mathrm{MO}$ colon adenocarcinomas: markers of reduced 
disease free survival and intra-abdominal metastases and their implications for TNM classification. Cancer. 2000;88:222838 .

17. Tocchi A, Mazzoni G, Lepre L, Liotta G, Costa G, Agostini N, et al. Total mesorectal excision and low rectal anastomosis for the treatment of rectal cancer and prevention of pelvic recurrences. Arch Surg. 2001;136:216-20.

18. Tateishi S, Arima S, Futami K, Kawahara K, Tachikawa D, Naritomi K, et al. A clinicopathological investigation of "tumor nodules" in colorectal cancer. Surg Today. 2005;35:377-84. 